\title{
SIMPLE GAMIFICATION FOR SCHOOL AGE STUDENTS \#NGAJARDARIRUMAH2.0
}

\author{
Pierre Mauritz Sundah, Christa Olivia Geraldine \\ Universitas Pelita Harapan \\ christa.geraldine@uph.edu,pierre.sundah@uph.edu
}

\begin{abstract}
Abstrak
Satu tahun telah berlalu sejak COVID-19 pertama kali diumumkan di Indonesia menyebabkan Sektor Pendidikan melakukan perubahan Kegiatan Belajar Mengajar (KBM) secara tatap muka menjadi KBM secara daring. Secara perlahan institusi pendidikan telah menyesuaikan diri baik dari tenaga pendidik maupun peserta didik. Namun permasalahan tidak berhenti begitu saja, muncul beberapa permasalahan baru seperti rasa jenuh yang dialami oleh peserta didik. Berdasarkan pengamatan kami, peserta didik merasa jenuh selama belajar daring dikarenakan kelas yang padat dengan tugas yang diberikan. Selain itu persiapan dan kemampuan tenaga pendidik yang masih dalam tahap menyesuaikan diri juga menjadi kendala. Berawal dari kegiatan PkM \#NGAJARDARIRUMAH yang telah diadakan sebelumnya dalam bentuk webinar mengenai penggunaan Google Classroom dalam meningkatkan kemampuan tenaga pendidik, maka kami PJJ Ilmu Komunikasi UPH mengadakan kegiatan lanjutan mengenai pengelolaan kelas daring dengan menggunakan teknik Gamifikasi sederhana untuk siswa usia sekolah. Kegiatan ini kami tujukan untuk tenaga pendidik dari tingkat TK hingga SMA di seluruh Indonesia agar tenaga didik dapat membuat kelas lebih menyenangkan dan meningkatkan semangat peserta didik dalam mengikuti KBM. Para peserta antusias dalam mengikuti kegiatan dengan salin berbagi informasi dan pengalaman serta semakin memahami pentingnya kreatifitas untuk mencegah kejenuhan dalam kelas daring. Peserta berharap kegiatan seperti ini dapat diadakan secara berkala
\end{abstract}

Kata_kunci_; gamifikasi, kelas daring, literasi digital

\section{PENDAHULUAN}

Tujuh bulan telah berlalu sejak kasus COVID-19 pertama di Indonesia yang terdeteksi pada bulan Maret 2020. Situasi darurat pandemi yang berkepanjangan memaksa Menteri Pendidikan dan Kebudayaan (Mendikbud), Nadiem Anwar Makarim, untuk mengeluarkan Surat Edaran Menteri No. 4 tahun 2020 mengenai Pelaksanaan Kebijakan Pendidikan dalam Masa Darurat Penyebaran CoVID-19. Surat edaran Menteri ini dikeluarkan sebagai salah satu implementasi upaya pencegahan oleh Kementerian Pendidikan dan Kebudayaan (Kemendikbud) demi mencegah penyebaran COVID-19 dalam klaster institusi pendidikan, baik dalam ranah pendidikan dasar hingga pendidikan tinggi. Surat edaran Menteri tersebut memberikan arahan tegas agar proses belajar mengajar yang semula diadakan secara tatap muka dialihkan menjadi pendidikan jarak jauh, yang dilaksanakan secara dalam jaringan (daring). Perubahan mendadak yang dilakukan tentunya dibuat dengan persiapan yang minim, sehingga 
mengakibatkan banyak pihak tidak siap mengadakan kegiatan belajar mengajar (KBM) daring, baik pada sisi peserta didik maupun tenaga pendidik (Angdhiri, 2020). Melihat kondisi demikian, maka Program Studi (prodi) Pendidikan Jarak Jauh (PJJ) Universitas Pelita Harapan (UPH) telah mengadakan kegiatan Pengabdian kepada Masyarakat (PkM) pada bulan Mei 2020 untuk membantu tenaga pendidik di Indonesia memperlengkapi diri agar lebih siap menghadapi KBM secara daring. PJJ Ilmu Komunikasi UPH mengadakan PkM dengan tema \#ngajardarirumah dengan mengangkat literasi digital sebagai tema besarnya. Kegiatan PkM ini merupakan kelanjutan dari kegiatan PkM yang telah dilaksanakan pada tahun sebelumnya dengan tema yang sama.

Berbekalkan kemampuan melaksanakan $\mathrm{KBM}$ secara daring yang terbatas, tenaga pendidik secara umum cenderung melakukan KBM menggunakan media daring untuk menggantikan KBM tatap muka sedekat mungkin dengan pelaksanaan luringnya. Rata-rata proses KBM dilakukan secara sinkronus menggunakan platform video conference, dan dikombinasikan dengan tugas mandiri yang harus dikerjakan oleh peserta didik. Pelaksanaan seperti demikian membuat para peserta didik merasa bahwa tugas yang diberikan terlalu banyak. Selain itu, frekuensi pengadaan kelas sinkronus yang padat tanpa diimbangi dengan interaksi sosial satu dengan lainnya dirasa membebani. Tidak sedikit peserta didik yang mengalami kebingungan dalam proses belajar karena absennya peran tenaga pendidik yang siap diajak berkonsultasi tentang materi pembelajaran seperti pada saat KBM tatap muka. Kesulitan seperti ini tidak hanya dirasakan oleh pihak peserta didik saja, tetapi juga oleh para tenaga pendidik. Tenaga pendidik seperti guru dan dosen perlu mempersiapkan materi ajar yang dapat digunakan secara daring, serta beradaptasi dengan teknik baru penggunaan platform digital seperti Learning
Management System (LMS) dalam melaksanakan KBM. Selain itu, tenaga pendidik juga harus berusaha membuat proses pembelajaran daring menjadi menyenangkan, agar para peserta didik tidak merasa bosan dan pemahaman materi menjadi kurang maksimal.

\section{METODE}

Kegiatan PkM ini dilaksanakan secara daring dengan menggunakan aplikasi Zoom dengan tahapan sebagai berikut:

a. Persiapan

\section{i. Penentuan topik kegiatan}

ii. Pembuatan materi publikasi

iii. Persiapan materi

iv. Persiapan teknis (pembuatan ruang Zoom meeting, penyediaan webcam, komputer, dll)

b. Pelaksanaan

v. Simulasi pelaksanaan

i. Briefing

ii. Pembukaan

iii. Pemaparan Materi

iv. Tanya jawab dan sharing

c. Evaluasi

Dalam pelaksanaan kegiatan, peserta terlihat antusias dalam mengikuti sesi sharing yang diberikan. Hal ini dapat dilihat dari pertanyaanpertanyaan yang diberikan kepada pemateri. Selain itu juga terdapat peserta yang ikut membagikan pengalamannya dalam menjalankan KBM dengan menggunakan gamifikasi secara sederhana.

Kegiatan sudah berjalan dengan baik, namun masih terdapat beberapa hal yang masih dapat ditingkatkan. Salah satu faktor yang ingin disoroti adalah ketidaksesuaian jumlah peserta yang tercantum dalam data pendaftaran dengan jumlah peserta yang hadir dan berpartisipasi pada hari pelaksanaan kegiatan. Penurunan jumlah peserta yang hadir tercatat mencapai $60 \%$ dari total jumlah peserta yang mendaftar, sehingga dapat dibilang cukup signifikan. Selain itu, diharapkan bahwa kegiatan webinar dengan tema serupa dapat dilakukan dalam bentuk workshop di waktu-waktu ke depannya, sehingga peserta bisa memperoleh 
alokasi waktu diskusi dan praktek secara seimbang. Sebagai contoh, peserta dapat memanfaatkan alokasi waktu praktek untuk bersama-sama merencanakan suatu simulasi proses KBM yang baik dengan menggunakan konsep dan elemenelemen gamifikasi. Hal ini dikarenakan proses KBM dengan gamifikasi membutuhkan sebuah persiapan konsep yang matang, di mana tenaga pendidik disarankan untuk memasukkan unsurunsur permainan ke dalam pelajaran, sehingga KBM dapat berjalan dengan lebih menyenangkan. Tidak hanya mengutamakan unsur kesenangan semata, tetapi diimbangi dengan keberadaan aspek pembelajaran yang berkualitas.

\section{HASIL DAN PEMBAHASAN}

\section{Pelaksanaan Kegiatan}

Pelaksanaan kegiatan PkM Simple Gamification ini dilangsungkan pada hari Kamis, 12 November 2020 secara daring menggunakan aplikasi Zoom. Kegiatan ini ditujukan kepada para tenaga pendidik di seluruh Indonesia dengan tujuan untuk dapat memperlengkapi para tenaga pendidik dalam melakukan KBM yang tidak membosankan bagi para peserta didik yaitu dengan menggunakan teknik gamifikasi.

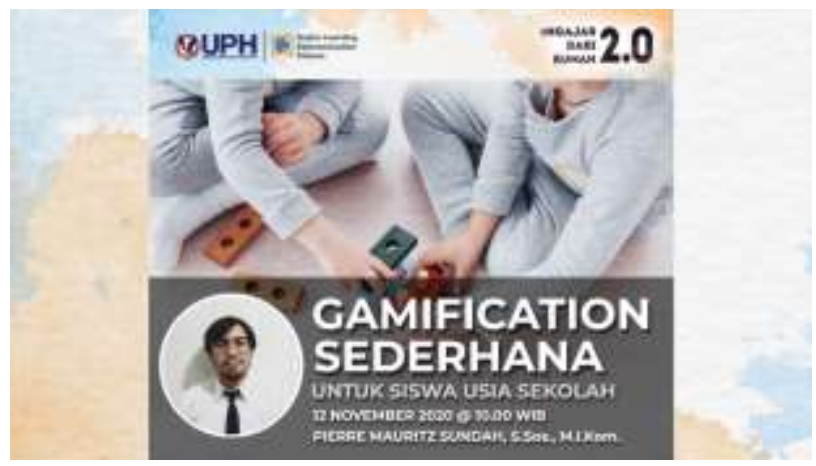

Gambar 1. Poster Kegiatan

Dalam pelaksanaan PkM, pemateri berupaya menerapkan beberapa teknik gamifikasi dalam penjelasannya dengan tujuan agar para peserta dapat membayangkan secara langsung seperti apa proses penerapan gamifikasi dalam KBM. Penyampaian materi dimulai dengan memberikan gambaran situasi dalam sebuah permainan yang disimulasikan dalam sebuah file PowerPoint. Sembari sebuah narasi pembuka dibacakan, sebuah set audiovisual diluncurkan untuk mendukung suasana pembukaan presentasi materi. Pemberian narasi tersebut bertujuan agar para peserta juga merasakan situasi yang mungkin juga akan dirasakan oleh para peserta didik dalam kelas. Penerapan konsep yang menyeluruh seperti ini juga merupakan inti penting yang diperlukan dalam sebuah proses gamifikasi materi, yaitu membuat peserta merasakan berada dalam dunia yang sesuai dengan konsep gamifikasi yang kita siapkan sebagai tenaga pendidik. Dalam hal ini, pemateri dan host bekerja sama untuk menciptakan suasana yang mendukung sesuai dengan konsep yang telah dipersiapkan.

Materi dimulai dengan perkenalan elemenelemen klasik dalam gamifikasi, seperti sistem poin, penghargaan, dan papan skor teratas. Pemateri kemudian menjelaskan tentang mengapa unsur permainan dianggap penting dan esensial dalam sebuah proses pembelajaran, serta alasan dorongan dalam diri manusia yang dipadatkan dalam konsep Octalysis Framework. Konsep ini merupakan konsep yang diangkat oleh Yukai-Chou sebagai salah satu pakar dalam hal gamifikasi. Octalysis Framework mengangkat delapan inti yang dapat menggerakan atau mendorong manusia yaitu meaning, accomplishment, empowerment, unpredictability, scarcity, social influence, ownership dan avoidance.

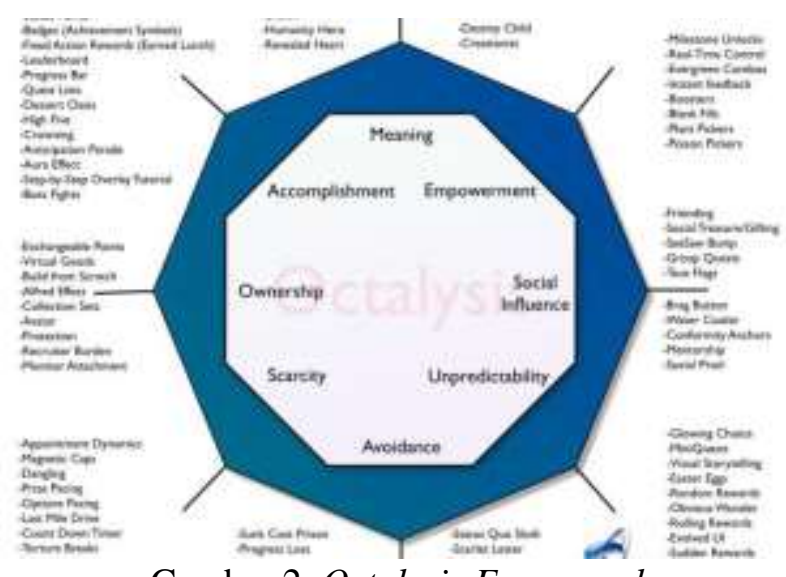

Gambar 2. Octalysis Framework 
Octalysis framework menjadi salah satu materi penting yang diberikan oleh pemateri dikarenakan framework tersebut merupakan inti dari sebuah gamifikasi menurut Yukai-Chou. Untuk dapat memahami dan mengaplikasikan gamifikasi dengan baik maka diperlukan pemahaman yang baik mengenai hal-hal yang dapat mengerakkan manusia. Setelah memahami delapan hal tersebut maka proses pengaplikasian gamifikasi dalam berbagai bidang menjadi lebih mudah.

Berikutnya, dijelaskan langkah-langkah penerapan yang dapat diimplementasikan ke dalam sebuah proses pembelajaran, yakni mendefinisikan konteks, mengidentifikasi tujuan pembelajaran, memberikan struktur pada pengalaman pembelajaran secara total, mengidentifikasi sumber daya yang dapat digunakan, dan mengaplikasikan elemen gamifikasi ke dalamnya.

Kemudian, pemateri memperkenalkan beberapa platform yang tersedia secara cuma-cuma seperti PearDeck, Kahoot, Quizizz, dan Menti.com. Pemaparan contoh beberapa platform ini merupakan upaya untuk memberdayakan peserta dengan menyediakan sumber daya yang telah tersedia secara publik dalam dunia maya, agar peserta dapat mempelajari penerapan fitur elemen gamifikasi yang disediakan oleh platform-platform tersebut. Dari kesemua contoh platform gamifikasi yang ada, pemateri menyampaikan prinsip-prinsip utama yang dikandung oleh setiap contoh penerapan gamifikasi melalui berbagai platform tersebut. Nantinya, peserta diharapkan dapat menerapkan elemen gamifikasi sederhana dalam proses pembelajaran masing-masing dengan menggunakan platform cuma-cuma ini, serta mencantumkan prinsip-prinsip kunci dari sebuah gamifikasi ke dalam proses yang sama.

Setelah melakukan pemaparan materi mengenai gamifikasi dibuka sesi tanya jawab dan berbagi cerita atau pengalaman selama melakukan KBM secara daring. Hal ini bertujuan untuk para peserta tidak hanya aktif bertanya tetapi juga dapat saling membagikan pengalaman, tips dan trik dalam mengaplikasikan gamifikasia dalam KBM. Terlihat para peserta antusias dalam membagikan cerita mereka sehingga membuat sesi tanya jawab ini menjadi lebih hidup.

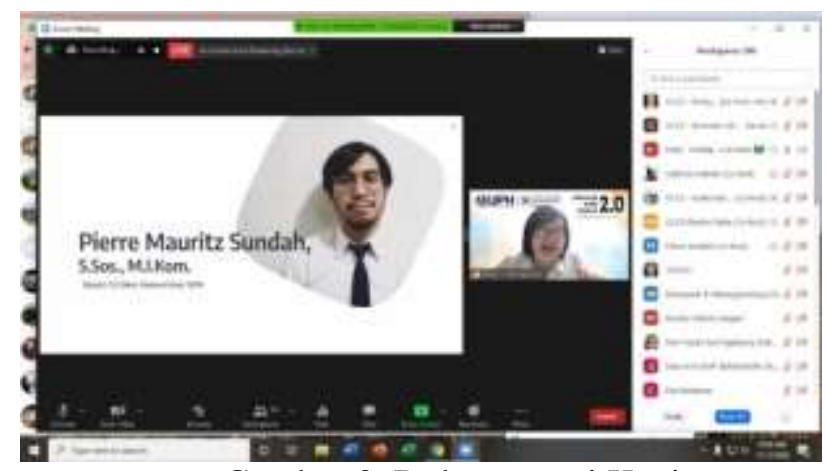

Gambar 3. Dokumentasi Kegiatan

Setelah sesi tanya jawab dan sharing selesai, tim pelaksana menayangkan sebuah survei singkat mengenai pelaksanaan kegiatan. Survei ini dilaksanakan melalui fitur survei dari Zoom yang sudah terintegrasi dengan platform konferensi video tersebut. Survei ini diadakan untuk mengumpulkan masukan, kritik, dan saran bagi pemateri dalam meningkatkan kualitas pemaparan materi serta menjadi dasar dalam melakukkan pengembangan materi untuk kegiatan-kegiatan berikutnya.

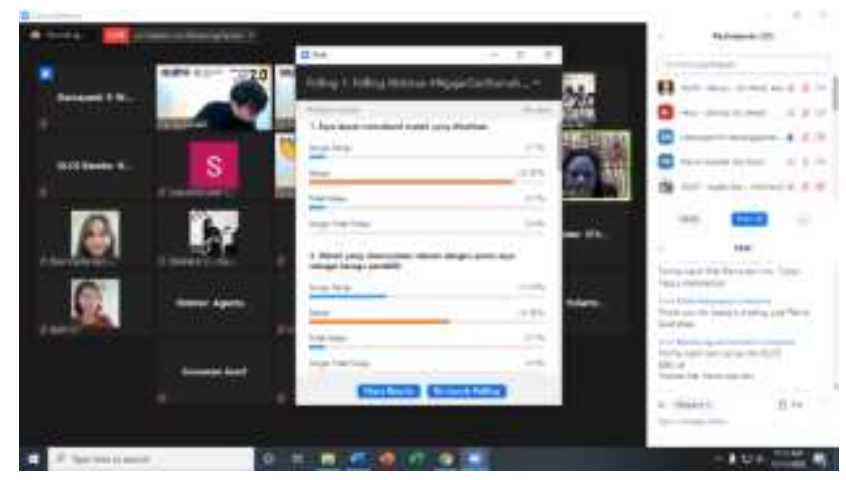

Gambar 4. Polling terkait pelaksanaan kegiatan

Berdasarkan survei singkat tersebut, dapat dilihat bahwa peserta memahami materi yang diberikan, dan materi yang diberikan juga tidak dirasa membosankan. Dapat disimpulkan bahwa usaha pemateri dalam memberikan konsep gamifikasi dalam pemberian materi berhasil diterima dengan baik oleh peserta. 


\section{KESIMPULAN}

Kegiatan PkM ini diadakan untuk membantu para tenaga pendidik agar dapat lebih memahami dan memiliki kemampuan dalam mempersiapkan KBM yang baik untuk para peserta didik. Harapannya apa yang disampaikan dalam PkM ini dapat digunakan dan diterapkan pada KBM. Para peserta juga diharapkan dapat memberikan waktu dan tenaga lebih dalam mempersiapkan konsep dan materi yang akan digunakan dalam KBM. Untuk kegiatan berikutnya, terutama terkait publikasi dan penyebaran tautan Zoom, kiranya dapat didistribusikan dengan lebih terbuka dan disosialisasikan kembali, karena banyak peserta yang tidak menyadari bahwa tautan Zoom sudah dikirimkan setelah peserta melakukan pendaftaran. Hal ini merupakan salah satu faktor penyumbang penurunan jumlah peserta sebesar $60 \%$ dari jumlah pendaftar pada saat kegiatan dilaksanakan.

\section{REFERENSI}

Aini, Q., Rahardja, U., Moeins, A., \& Wardani, A. M. (2018). Penerapan Data Market Query (DMQ) pada Sistem Penilaian Berbasis Yii Framework. InfoTekJar (Jurnal Nasional Informatika Dan Teknologi Jaringan). https://doi.org/10.30743/infotekjar.v3i1.565

Angdhiri, R. P. (2020). Challenges of home learning during a pandemic through the eyes of a student - Lifestyle - The Jakarta Post. The Jakarta Post.Com.

Chou, Y. (2019). Actionable Gamification: Beyond Points, Badges and Leaderboards. 